\title{
Reseña: Jean-Marie Schaeffer, Arte, objetos, ficción, cuerpo. Cuatro ensayos sobre estética. Editorial Biblos, Colección Pasajes, Buenos Aires, 2012. 124 pp.
}

\section{Chantal Paula Rosengurt}

Tal como pone de manifiesto su título, el libro reúne cuatro ensayos sobre estética que abordan desde una mirada contemporánea cuestiones relativas al arte, sus "objetos", a la ficción, y al cuerpo. La breve compilación que constituye da cuenta del programa filosófico y de las líneas de investigación que el autor ha trazado desde principios de los años noventa hasta la actualidad, reuniendo aportes de la filosofía tanto como de la antropología y las neurociencias. Es importante señalar que esta obra cuenta con el aporte de Ricardo Ibarlucía, quien ha realizado la traducción al castellano, la edición de los ensayos incluidos, y un prólogo que se destaca por su completitud y profundidad en la articulación del presente libro con el resto de la obra del autor. En él, Ibarlucía llama la atención sobre la evolución que ha tenido lo que llama la "nueva filosofía", esto es, una filosofía con ideales de claridad y consecuencia, ideas de lógica, verdad y demostración de la cual considera a Schaeffer fiel representante. La edición también incluye un apéndice bibliográfico con obras del autor que van desde el año 1983 al 2012, abarcando libros, dirección de obras colectivas y números de revistas, textos en obras colectivas, separatas, principales artículos, prefacios y traducciones.

El primero de los cuatro ensayos, "La Teoría especulativa del Arte" remite a una conferencia leída el 15 de diciembre de 1994 en el Institut d'Art Contemporain del Nouveau Musée de Villeurbanne en la que recupera la tesis principal de L'art de l'áge moderne. L'esthétique et la philosophie de l'art du XVIIIe siècle à nos jours, publicada en 1992. El trabajo se encuentra orga-

\footnotetext{
* Licenciada en Psicología (Universidad Nacional de La Plata) desde 2012, Doctoranda en Filosofía (UNLP, Instituto de Investigaciones en Humanidades y Ciencias Sociales, CONICET), Sus trabajos de investigación se centran en cuestiones estéticas y gnoseológicas relativas al pragmatismo, y al pensamiento de John Dewey y JeanMarie Schaeffer. Dirección electrónica: chantalprosengurt@gmail.com
} 
nizado en dos partes. La primera de ellas, está abocada a la conceptualización de lo que denomina una "Teoría especulativa del Arte", producto del romanticismo alemán, cuya tesis central reza: "El arte es un saber extático, es decir, que revela verdades trascendentes, inaccesibles a las actividades cognitivas profanas" (p. 22). En cuanto a sus premisas y fundamentos, Schaeffer considera que dicha teoría nace como respuesta a una doble crisis espiritual y existencial: la de los fundamentos religiosos, y la de los fundamentos trascendentes de la filosofía derribados por Kant. El ensayo recorre algunas figuras cuyo pensamiento ha influenciado en ella: Hegel, Nietzsche, Benjamin, Adorno, y principalmente, Schopenhauer; así como algunos de sus exponentes artísticos: Gauguin, Proust, Malévitch, Mondrian, Wagner y Schönberg. La segunda parte del trabajo expone tesis críticas del autor que se fundamentan en la filosofía kantiana, y la consideración de ciertas consecuencias negativas que la teoría ha implicado. Schaeffer sostiene que la teoría especulativa del arte ha propiciado un discurso -en palabras de Ibarlucía- "autolegitimador e inverificable" sobre el arte y la literatura, a partir de la confusión epistemológica que ha generado entre la descripción analítica de los hechos artísticos y el juicio evaluativo, falseando ampliamente nuestra relación con las obras de arte, llegando incluso a desconocer y reducir la lógica propia de la dimensión estética a la artística.

“¿Objetos estéticos?” es un ensayo publicado en L'Homme, Revue francaise d'anthropologie ( $N^{\circ}$ 170: Espèces d'objects, 2004/2) que ahonda en cuestiones tratadas en Les célibataires de l'art, y en Théorie des signaux couteux, esthétique et art (2009). En él analiza críticamente la noción de "objeto estético" y sus diferentes acepciones, enmarcadas en lo que denomina un "rodeo ontologizante", (rasgo del pensamiento occidental que es parte de una compulsión a la ontologización de lo real, sustancializadora y objetivante). Schaeffer sostiene que dicha concepción es correlativa al nacimiento de la Estética como disciplina filosófica, efecto colateral de la filosofía del arte romántica e idealista del siglo XIX. Sostiene que si bien tal rodeo ha tenido sus ventajas, no está justificado, además de haber dificultado el pensamiento acerca de todo lo que procede de lo factual y lo procesal, cercano a la noción de Befindlichkeit de Martin Heidegger. "Pensar la dimensión estética en términos de objetos nos impide el acceso a la realidad de los hechos estéticos" (p. 56). En el abordaje alternativo que propone, Schaeffer sostiene que en el dominio de las artes la "dimensión estética no procede de una propiedad ontológica de los objetos, sino de un tipo de activación mental de esos objetos.” (p. 64), 
situando como premisa fundamental los estudios de Hume y Kant sobre el gusto. La propuesta procura un desplazamiento de la concepción tradicional esencialista a una aproximación genética del principio de señalización costosa, del "objeto estético" a la "relación estética", y opera una reformulación del concepto de "obra de arte". La tesis más fuerte que el trabajo expone es la de la no existencia de "objetos" estéticos, y por ende de propiedades "estéticas". Se trata, para el autor, de objetos y otras realidades que pueden ser o no ser investidos estéticamente, actividad mental (intencional) y biológica que supone una atención cognitiva y una cuota de (dis)satisfacción.

"De la imaginación a la ficción", es un trabajo que amplía cuestiones desarrolladas por Schaeffer en Pourquoi la fiction? (1999), publicado en diciembre de 2002 en la revista Vox Poetica. Lettres et sciences humaines, editada por la Societé Francaise de Littérature Générale et Comparée. El trabajo, de una riqueza conceptual admirable, sólo comparable con la capacidad de síntesis que aquí demuestra el autor, aborda desde una perspectiva pragmática, por contraposición a una concepción semántica, el estatuto de las representaciones imaginarias, haciendo hincapié en lo que considera su función cognitiva, posición desde la cual discute con la perspectiva platónica. Schaeffer se remite al estudio matemático de los números imaginarios para sostener como hipótesis general: "en ciertas situaciones, lo imaginario no sólo no nos impide llegar a lo real sino que es una condición indispensable para alcanzarlo" (p.83). La mención a las funciones endotélica y compensatoria de las representaciones imaginarias es situada en relación a estudios de Martin Heidegger y Sigmund Freud. Schaeffer se pregunta por los lazos entre imaginación y ficción, distinguiendo entre estas últimas a la "ficción lúdica", una de las aplicaciones de lo imaginario, de la "ficción instrumental", distinción que es puesta en serie con los análisis al respecto realizados por David Hume y Jeremy Bentham. En su propio análisis de la ficción, a la que toma en el sentido platónico de la semejanza, pero también en el aristotélico en tanto creadora de un modelo de la realidad, Schaeffer se aboca a la relación de la ficción con la mímesis o imitación, con la esfera artística, y con lo real. En cuanto a la ficción lúdica concebida como proceso mimético, el autor ofrece lo que considera tres elementos o mecanismos constitutivos de aquella: "la simulación lúdica"; "la inmersión mimética"; y "la modelización analógica". El trabajo concluye con una revisión de las múltiples funciones de las experiencias virtuales de los universos ficcionales. 
"El cuerpo es imagen" es un artículo publicado en Image \& Narrative. Online Magazine of the visual Narrative ( $N^{\circ} 154$; Battles around Images: Iconoclasm and Beyond), en noviembre de 2006, basado en su colaboración en la exposición colectiva de antropología ¿Qué es un cuerpo?, del Musée du Quai Branly de París, inaugurada en junio de 2006. El trabajo despliega la hipótesis según la cual "la importancia de la imagen en nuestra tradición cultural -occidentaly cristiana- depende del hecho de que es el lugar del pensamiento del cuerpo" (p. 103). El autor sostiene que nuestra tendencia a pensar conjuntamente el tema de la imagen y del cuerpo, posee tres fuentes principales: el dualismo, el creacionismo monoteísta, y el pensamiento de la encarnación, que es la tesis de Dios hecho hombre. Y afirma que tal tendencia, a partir de la Edad Media, ha empujado un proceso de interiorización cada vez más fuerte del modelo, en una permanente tensión entre éste y la imagen correspondiente. A través del desnudo en la pintura, el autor ejemplifica la tensión entre la imagen conforme (al modelo) o disconforme, como una oscilación entre la elevada belleza y la degradación de la imagen a la calidad pornográfica. Los desarrollos contemporáneos de la genética, sostiene, reproducen esa tensión entre modelo e imagen, genotipo y fenotipo, velando la angustia por la pregunta que subyace: ¿qué sucedería si el modelo estuviera viciado por un principio de entropía constitutivo, si el modelo mismo fuera el productor de monstruos?

En suma, esta obra, aunque pequeña por su longitud, constituye una referencia de gran relevancia para aquellos dedicados al estudio de estas cuestiones, capaz de proporcionar respuestas a diversos problemas planteados por la filosofía estética moderna y contemporánea.

Recibido: 9/2014; aceptado: 10/2014 